IUUS IUS

\title{
Las competencias municipales otorgadas por el artículo 115 de la Constitución y su relación con los derechos humanos y el mantenimiento y promoción de la salud pública*
}

Municipal power granted by the article 115 of the Constitution and its relationship to human right and the maintenance and promotion of public health

\author{
Alina del Carmen Nettel Barrera**
}

\section{RESUMEN}

Este artículo tiene por objetivo analizar las competencias otorgadas por la Constitución Politica de los Estados Unidos Mexicanos a los municipios desde una perspectiva critica que promueva el reconocimiento de las obligaciones básicas que tienen las administraciones públicas municipales en materia de salud. Dicho análisis se desarrolla a partir de la interpretación conjunta de los artículos 1 y 115 de la Constitución, que imponen a las autoridades la obligación de promover, respetar, proteger y garantizar los derechos humanos, entre ellos el derecho a la salud.

PALABRAS CLAVE: Derecho a la salud, derechos humanos, administraciones locales, municipios, agua, medio ambiente saludable.

\section{ABSTRACT}

This article aims to analyze the powers granted by the Political Constitution of the United Mexican States to municipalities, from a critical perspective, that promotes the recognition of basic obligations of municipal public administrations in health today. This analysis is a joint interpretation of the Articles 1 and 115 of the Constitution which impose on the authorities the obligation to promote, respect, protect and guarantee human rights, including the right to health.

KEY WORDS: Right to health, human rights, local governments, municipalities, water, healthy environment.

* Recibido: 22 de enero de 2013. Aceptado: 4 de marzo de 2013.

**Profesora de tiempo completo en la Universidad Autónoma de Querétaro, México (alinanettel@hotmail.com). 
ALINA DEL CARMEN NETTEL BARRERA

\section{Sumario}

1. Introducción

2. El derecho a la salud en los tratados internacionales y en el ordenamiento mexicano

A) El derecho a la salud y los instrumentos internacionales de protección de los derechos humanos

B) El derecho a la salud en el ordenamiento mexicano

3. Las competencias otorgadas a los municipios por el artículo 115 de la Constitución mexicana

4. Los derechos humanos y la actuación de las autoridades municipales en relación con la protección de la salud

5. Conclusiones

\section{Introducción}

La Constitución mexicana reconoce el derecho a la protección de la salud en el artículo 4, bajo un régimen de concurrencia de competencias entre la Federación y las entidades federativas. Este marco competencial debe entenderse complementado y en íntima relación con el desempeño de las administraciones municipales porque, por una parte, como unidad política y administrativa más cercana a los ciudadanos, el municipio juega un papel esencial en materia de salubridad, ${ }^{\prime}$ lo que ha reconocido la propia Constitución en la fracción 11 del artículo 115 al explicitar una serie de competencias específicas, todas ellas relacionadas con la salubridad o con la seguridad pública. Por otra parte, en el contexto constitucional actual, todas las autoridades mexicanas tienen la obligación de velar por la protección de los derechos humanos en su determinado ámbito competencial. En este sentido, los ayuntamientos juegan un papel trascendental si tomamos en cuenta la importancia de la salud en la mejora de la calidad de vida de los ciudadanos.

Se debe señalar que este trabajo no tiene como principal objetivo la capacidad de los ayuntamientos para asumir la prestación de los servicios de salud directamente, pues incluso siendo ésta una posibilidad jurídicamente viable, una vez iniciado el proceso descentralizador en 1984, la siempre problemática cuestión económica impide que pueda concretarse este fin. Por otra parte, la actua-

1 La salubridad, en términos de la Real Academia Española de la Lengua, es una cualidad de lo salubre, y este último término se refiere a lo que es bueno para la salud. No es una cuestión de menor importancia reconocer que la locución no degrada o extingue su relación con el derecho a la salud, pues precisamente en este punto subyace una de las principales consecuencias de la poca importancia o mera instrumentalización con la que algunos municipios ejercen las competencias otorgadas por la Constitución. Véase Real Academia Española de la Lengua, Diccionario de la lengua española, Espasa-Calpe, Madrid, 2012 [En línea], disponible en: www.rae.es. 
ción de las autoridades administrativas municipales, en relación con el derecho a la salud, no puede estar condicionado a la prestación de servicios médicos, pues se trata de un campo más amplio de acción. El derecho a la salud, recogido en el Protocolo Adicional a la Convención Americana sobre Derechos Humanos en materia de Derechos Económicos, Sociales y Culturales y en la propia Constitución, es el punto de partida de esta investigación, que aborda desde una perspectiva crítica el papel que juega este derecho en el ámbito municipal en el marco de las competencias específicas que la Constitución mexicana otorga.

\section{El derecho a la salud en los tratados internacionales y en el ordenamiento mexicano}

\section{A) El derecho a la salud y los instrumentos internacionales de protección de los derechos humanos}

Para comprender el verdadero alcance que tiene en la actualidad el derecho a la salud y su correlativa obligatoriedad en el quehacer de las administraciones públicas locales, debemos reconocer que su proceso histórico exige considerar a los derechos de segunda generación como obligaciones positivas para los gobiernos y no como meras expectativas para los ciudadanos. En el marco de los compromisos internacionales asumidos por el Estado mexicano, el artículo 12 del Pacto Internacional de Derechos Económicos, Sociales y Culturales compromete al reconocimiento del "derecho de toda persona al disfrute del más alto nivel posible de salud física y mental", señalando una serie de medidas que los Estados que suscriben o se adhieren al Pacto deben adoptar a fin de asegurar la efectividad del derecho a la salud:

a) La reducción de la mortinatalidad y de la mortalidad infantil, y el sano desarrollo de los niños;

b) El mejoramiento en todos sus aspectos de la higiene del trabajo y del medio ambiente;

c) La prevención y el tratamiento de las enfermedades epidémicas, endémicas, profesionales y de otra índole, y la lucha contra ellas;

d) La creación de condiciones que aseguren a todos asistencia médica y servicios médicos en caso de enfermedad.

Todas estas medidas, con mayor o menor acierto, son abordadas por la legislación mexicana, ya sea en materia de salud o de trabajo, pero se debe poner 
énfasis en el nuevo significado que cobran aspectos como la prevención, tratamiento y lucha contra las enfermedades que representan un serio peligro para la salud desde diversas perspectivas, como el alcoholismo, ${ }^{2}$ del cual se estima que ocupa el tercer lugar entre los principales factores de riesgo de muerte prematura y discapacidad a nivel mundial.

El Pacto Internacional de Derechos Económicos, Sociales y Culturales es un instrumento en continua evolución a través del Comité de Derechos Económicos, Sociales y Culturales de las Naciones Unidas, el cual supervisa la aplicación del Pacto. Para conseguir sus objetivos, el Comité publica la interpretación de las disposiciones a través de documentos conocidos como observaciones generales. En el año 2000, el Comité emitió la Observación General número 14, "El derecho al disfrute del más alto nivel posible de salud", en relación con el artículo 12 del Pacto. En este instrumento no sólo se especifica que el derecho a la salud está estrechamente vinculado y depende del ejercicio de otros derechos humanos como el derecho a la igualdad o a una vida digna, del cual se desprende el derecho al agua, ${ }^{3}$ sino que también reconoce que el artículo 12 del Pacto no se limita a la atención oportuna y apropiada de las enfermedades, pues comprende otros factores determinantes de la salud e incluso la participación de la población en el proceso de toma de decisiones relacionadas con la salud en los planos comunitario, nacional e internacional. Sobre la efectividad del Pacto se debe recordar que en 1998 se adoptó la Observación General sobre la aplicación interna del Pacto, por la cual se especifica que no sólo los recursos judiciales son fundamentales para garantizar los derechos consagrados en el mismo, sino que, también, "sobre la base del principio de buena fe, todas las autoridades administrativas, al adoptar decisiones, tendrán en cuenta las disposiciones del Pacto”, tal como se reconoce actualmente en México tras las reformas constitucionales de junio de 2011.

Por su parte, la Convención Americana sobre Derechos Humanos (Pacto de San José) recoge en su artículo 4 el derecho a la vida, a partir del cual -y en relación con la obligación de respetar los derechos contenidos en la Convención-

\footnotetext{
${ }^{2}$ La gravedad de esta enfermedad de índole epidémica y su impacto negativo en diversas áreas de la salud y, por ende, en el desarrollo social, económico y cultural de los paises ha llevado a la Organización Mundial de la Salud (oms) a poner en marcha la Estrategia Mundial para Reducir el Uso Nocivo del Alcohol (avalada por la 63a Asamblea Mundial de la Salud en 2010). En México, la Estrategia de la oms tiene repercusión en diversos programas nacionales, como el Sistema de Vigilancia Epidemiológica de las Adicciones (SISVEA) y los observatorios Nacional y Estatales en Alcohol, Tabaco y otras Drogas.

${ }^{3}$ La importancia en el ámbito municipal de este derecho se pone de manifiesto a través de competencias especificas como la gestión de servicios públicos de agua potable, drenaje, alcantarillado, tratamiento y disposición de aguas residuales. Sobre el derecho al agua y la obligación de los Estados parte para la adopción de las medidas necesarias para el pleno ejercicio del derecho al agua, asi como sus implicaciones con la salud, véase la Observación General de Comité No. 15 de 2002, E/c.12/2002/11.
} 
se ha resuelto alguna cuestión relativa a las condiciones mínimas compatibles con la vida humana, condiciones de salud y la situación especial de niños y ancianos. ${ }^{4}$ Bajo este contexto, la Corte Interamericana ha señalado que el derecho a la vida "no comprende sólo el derecho de todo ser humano a no ser privado de la vida arbitrariamente, sino también el derecho a que no se generen condiciones que le impidan o dificulten el acceso a una existencia digna". Para conseguir tal objetivo los Estados deben asumir una posición de garante de este derecho con el objetivo de protegerlo y garantizarlo, así como de generar las condiciones de vida mínimas compatibles con la dignidad de la persona humana, ${ }^{5}$ en términos semejantes a los utilizados por la Organización de las Naciones Unidas.

Pese a la interpretación favorable de los artículos citados de la Convención, el instrumento que recoge específicamente el derecho a la salud es el Protocolo Adicional a la Convención Americana sobre Derechos Humanos en materia de Derechos Económicos, Sociales y Culturales, conocido como "Protocolo de San Salvador”, de noviembre de 1988. Este instrumento, firmado por México en el momento de su adopción, tiene por finalidad incluir en el régimen de protección de la Convención diversos derechos y libertades a través de su aprobación por la Asamblea General de la Organización de Estados Americanos. El Protocolo recoge en el artículo 10 el derecho a la salud y en el 11 el derecho a un medio ambiente sano. Ambos artículos determinan un conjunto de obligaciones sistemáticas para alcanzar una vida digna.

El derecho a la salud, de acuerdo con el artículo 10 del Protocolo, comprende:

1. Toda persona tiene derecho a la salud, entendida como el disfrute del más alto nivel de bienestar físico, mental y social.

2. Con el fin de hacer efectivo el derecho a la salud los Estados partes se comprometen a reconocer la salud como un bien público y particularmente a adoptar las siguientes medidas para garantizar este derecho:

\footnotetext{
4 Véase Caso Comunidad Indigena Yakye Axa vs. Paraguay, sentencia del 17 de junio de 2005. En este asunto, la Corte Interamericana de Derechos Humanos señaló que "no son admisibles enfoques restrictivos al derecho a la vida", pues este derecho humano no sólo comprende el no ser privado de la vida arbitrariamente sino también "el derecho a que no se generen condiciones que le impidan o dificulten el acceso a una existencia digna". Por otra parte, la misma sentencia señala que el Estado tiene la obligación de "generar las condiciones de vida mínimas compatibles con la dignidad de la persona humana y a no producir condiciones que la dificulten o impidan". En el caso de la comunidad indigena Yakye Axa, al ser desplazados de su asentamiento original, tuvieron que trasladarse a una zona en la que se vieron imposibilitados a acceder "a una vivienda adecuada dotada de los servicios básicos mínimos como agua potable y servicios sanitarios". Servicios públicos que los ayuntamientos mexicanos deben prestar.

${ }^{5}$ Caso Instituto de Reeducación del Menor vs. Paraguay, sentencia del 2 de septiembre de 2004; Caso de los Hermanos Gómez Paquiyauri vs. Perú, sentencia del 8 de julio de 2004; Caso Myrna Mack Chang vs. Guatemala, sentencia del 25 de noviembre de 2003; Caso de los "Niños de la Calle" (Villagrán Morales y otros) vs. Guatemala, sentencia del 19 de noviembre de 1999.
} 
ALINA DEL CARMEN NETTEL BARRERA

a. la atención primaria de la salud, entendiendo como tal la asistencia sanitaria esencial puesta al alcance de todos los individuos y familiares de la comunidad;

b. la extensión de los beneficios de los servicios de salud a todos los individuos sujetos a la jurisdicción del Estado;

c. la total inmunización contra las principales enfermedades infecciosas;

d. la prevención y el tratamiento de las enfermedades endémicas, profesionales y de otra índole;

e. la educación de la población sobre la prevención y tratamiento de los problemas de salud, y

f. la satisfacción de las necesidades de salud de los grupos de más alto riesgo y que por sus condiciones de pobreza sean más vulnerables.

Comprender el derecho a la salud desde la perspectiva de los deberes de las administraciones públicas municipales puede fundarse no sólo en las obligaciones que los Estados asumen frente a los tratados internacionales, sino también en la concepción de la salud como un bien público, el cual, por lo tanto, debe ser tutelado por todos los niveles de gobierno. Si bien esta interpretación es útil, lo cierto es que representa sólo una parte o un punto de vista menor.

Por su parte, el artículo 11 del Protocolo recoge el derecho a un medio ambiente sano, indicando en su apartado 1 que "toda persona tiene derecho a vivir en un medio ambiente sano y a contar con los servicios públicos básicos". Lo cual se complementa con el apartado 2, que señala: "Los Estados partes promoverán la protección, preservación y mejoramiento del medio ambiente". Bajo la perspectiva de la construcción jurisprudencial del derecho a la salud, el derecho a un medio ambiente sano y la prestación de servicios públicos básicos juegan un papel esencial en la protección del derecho a la vida. Un ejemplo lo constituyen las condiciones mínimas de salubridad e higiene que proporcionan los municipios al prestar los servicios de agua potable, saneamiento de aguas, gestión de residuos, distribución de alimentos a través de los mercados y centrales de abastos, o del rastro en el caso de ganado, sin olvidar la importancia del fomento a la salud mediante el adecuado mantenimiento y equipamiento de calles, parques y jardines públicos.

Los instrumentos internacionales establecen un parámetro amplio de actuación para los poderes púbicos, particularmente para las administraciones públicas, que tienen el deber de promover, respetar, proteger y garantizar los derechos humanos de acuerdo con una serie de principios reconocidos por la Constitución mexicana. Como ha señalado Miguel CARBONELl, el derecho internacional, a través de los actos, tratados, observaciones generales, etcétera, permite "advertir los distintos tipos de obligaciones que generan los derechos fundamentales para 
los poderes públicos" tanto generales como especificas, de tal suerte que el contenido del párrafo tercero del artículo 1 de la Constitución mexicana signifique actuaciones concretas para las autoridades administrativas en todos los niveles de gobierno. ${ }^{6}$

\section{B) El derecho a la salud en el ordenamiento mexicano}

El artículo 4 de la Constitución Política de los Estados Unidos Mexicanos no sólo reconoce el derecho a la protección de la salud sino también, entre otros, el derecho al medio ambiente y al agua. Una visión de conjunto de estos artículos recuerda la importante construcción de la jurisprudencia de la Corte Interamericana de Derechos Humanos y de la Organización de las Naciones Unidas en relación con la salud. La protección de la salud, según el artículo 4, es un derecho fundamental, bajo un régimen competencial de concurrencia entre la Federación y las entidades federativas. En este sentido, se remite al artículo 73, fracción $\mathrm{xV}$, para señalar como una competencia del Congreso federal la legislación en materia de salubridad general, dejando a los estados la capacidad de legislar en materia de salud local. Bajo este modelo, el sistema se distribuye entre la salubridad general, que corresponde a la Federación (y a los estados en materias concurrentes), y la salubridad local, que se reparte entre las entidades federativas y los municipios de acuerdo con la legislación estatal (leyes sectoriales y leyes orgánicas municipales). ${ }^{7}$ En el marco de desarrollo y establecimiento de competencias se debe recordar que las autoridades municipales son consideradas autoridades sanitarias por la mayoría de las legislaciones estatales, incorporándose, por esta vía, al sistema nacional de salud.

El derecho al medio ambiente, reconocido en el mismo artículo 4, señala que "toda persona tiene derecho a un medio ambiente sano para su desarrollo y bienestar. El Estado garantizará el respeto a ese derecho". Se señala, además, la determinación de responsabilidad para quien provoque daño o deterioro ambiental. En estos términos, parece diluirse la obligación del Estado de promover

${ }^{6}$ Véase Carbonell, Miguel. "Las obligaciones del Estado en el artículo $1^{\circ}$ de la Constitución mexicana", en Carbonell, M. y SALAZAR, P. (coords.). La reforma constitucional de derechos humanos. Un nuevo paradigma, Porrúa-unam, México, 2012, pp. 75-85. El autor señala, con fundamento en la Observación General 3 del Comité de Derechos Económicos, Sociales y Culturales de la onu, qué se debe entender por respetar (abstenerse de hacer cualquier cosa que viole la integridad de los individuos o grupos sociales o ponga en peligro la integridad de los individuos), proteger (adopción de medidas destinadas a evitar que otros agentes o sujetos violen los derechos fundamentales, a través de esquemas reactivos y preventivos) y cumplir o realizar (adopción de medidas activas, incluyendo acciones positivas a favor de grupos vulnerables) las obligaciones del Estado en materia de derechos fundamentales.

7 Sobre el desarrollo del sistema normativo en materia de salud véase Ruiz de Chávez, Manuel. La salud y el municipio, INAP, México, 1988, p. 50. 
la "protección, preservación y mejoramiento del medio ambiente" que recoge el artículo 11 del Protocolo Adicional a la Convención Americana sobre Derechos Humanos. Esta cuestión no es de escaza importancia, pues si bien la responsabilidad en materia medioambiental es importante, los operadores jurídicos (servidores públicos, jueces y abogados) y los ciudadanos debemos tener presente que el derecho a vivir en un medio ambiente sano también implica contar con servicios públicos básicos que lo garanticen, tal como lo ha venido señalando la Corte Interamericana de Derechos Humanos y diversos sectores de la doctrina. ${ }^{8}$

Por su parte, el derecho al agua recogido en el siguiente párrafo del artículo 4 de la Constitución involucra expresamente a los servicios municipales, pues establece la participación de la Federación, las entidades federativas, los municipios y la ciudadanía en el acceso y uso equitativo y sustentable de los recursos hídricos. En los términos de este artículo, el Estado garantizará que "toda persona tiene derecho al acceso, disposición y saneamiento de agua para consumo personal y doméstico en forma eficiente, salubre, aceptable y asequible". La importancia del ciclo del agua en la consecución del derecho a la salud es innegable y condiciona, desde la perspectiva de los derechos humanos, la actuación de las administraciones locales, particularmente municipales, en la gestión de los servicios públicos relacionados con el agua.

Por su parte, la Ley General de Salud, ley reglamentaria del artículo 4 constitucional, entre otros fines, establece el funcionamiento del sistema nacional de salud, el cual tiene por objeto dar cumplimiento al derecho a la protección de la salud. Este organismo está compuesto por las dependencias y entidades de la administración pública federal y local y tiene por objetivo, entre otros descritos en el artículo 6 de la Ley, "apoyar el mejoramiento de las condiciones sanitarias del medio ambiente que propicien el desarrollo satisfactorio de la vida". El reconocimiento de una concepción amplia del derecho a la salud y de las causas que atentan contra el ejercicio de este derecho ya se encuentra presente en la legislación nacional, pero disociada, en gran medida, del quehacer diario de las administraciones públicas, pues parece que la salud sólo se relaciona con la prestación de servicios médicos. Por otra parte, el artículo 7 de la misma norma señala que la coordinación del sistema nacional de salud estará a cargo de la Secretaría de Salud federal, la cual, entre otras acciones, impulsará la desconcentración y descentralización de los servicios de salud en la república mexicana. Esta encomienda es de gran importancia para el tema que nos ocupa, pues de

${ }^{8}$ Sobre la conceptualización del proceso de salud-enfermedad, la concepción global de la salud y la importancia del municipio en la promoción de la salud véase Sotelo, Juan Manuel. "Salud desde el municipio: una estrategia para el desarrollo", en Salud Pública de México, vol. 36 (4), 1994, disponible en: http://bvs.insp.mx/rsp/articulos/articulo. php?id=001715. 
la efectividad de las políticas y planes depende la concientización de las autoridades locales en materia de salud.

Se debe recordar que este trabajo no pretende abordar la capacidad de los municipios para prestar directamente servicios médicos, objetivo final de un proceso descentralizador iniciado en los años ochenta. ${ }^{9}$ Sin perjuicio de la importancia y las ventajas que puede traer consigo la asunción de servicios médicos de salud por parte de los municipios, se debe tener presente que la problemática económica y de recursos humanos imposibilita esta acción para los municipios más desfavorecidos. En cualquier caso, la tarea descentralizadora de servicios médicos pasa por la legislación de las entidades federativas, pues son sus legislaturas quienes tienen la capacidad de desarrollar el marco normativo y de colaboración que conduzca a los municipios de su ámbito territorial a la puesta en marcha de este tipo de servicios. El marco normativo de desarrollo de esta dinámica descentralizadora, a través del Poder Legislativo de las entidades federativas, encuentra su base en la coordinación de la competencia concurrente entre la Federación y los estados de la República prevista en el artículo 4 de la Constitución en relación con la ley reglamentaria, de acuerdo a la distribución de competencias prevista dentro del sistema nacional de salud por el artículo 13. Por otra parte, y en aplicación de la normativa desarrollada por sus propias legislaturas, la actividad material de las administraciones públicas locales, en el ámbito de la salud, se enmarca en los sistemas estatales de salud, en cumplimiento del artículo 9 de la Ley General, que encomienda:

Los gobiernos de las entidades federativas coadyuvarán, en el ámbito de sus respectivas competencias y en los términos de los acuerdos de coordinación que celebren con la Secretaría de Salud, a la consolidación y funcionamiento del sistema nacional de salud. Con tal propósito, los gobiernos de las entidades federativas planearán, organizarán y desarrollarán en sus respectivas circunscripciones territoriales, sistemas estatales de salud, procurando su participación programática en el Sistema Nacional de Salud.

\footnotetext{
${ }_{9}^{9}$ Este proceso se llevó a cabo por dos vías: legislativa y convencional (por reforma constitucional y convenios de coordinación). Véase Ruiz de Chàvez, MAnuel. "La salud y el...", op. cit., p. 45. La hemerografía relativa al proceso descentralizador es abundante, lo que demuestra la importancia de este paso en la superación de las deficiencias del sistema anterior, centralizado e inoperativo, a favor del desarrollo municipal, entre otros véase CARDozo BRUM, Miryam. "El papel del municipio en la descentralización de los servicios de salud", en Comercio Exterior, vol. 47, No. 10, 1997, pp. 795-799; Baz Diaz, Lombardo Gustavo. "Los servicios de salud en el municipio mexicano actual", en Gaceta Mexicana de Administración Pública Estatal y Municipal, No. 26-28, 1987; Ruiz de Chävez, Manuel y Lara Ponte, Rodolfo. "Los niveles de salud en el municipio mexicano actual", en Gaceta Mexicana de Administración Pública Estatal y Municipal, cit:; Morán Zenteno, José Antonio. "Los consejos municipales de salud, antecedentes, reglamentación y perspectivas", en Estudios Municipales, No. 5, 1985; Lara Ponte, Rodolfo y Herrera Zárate, Mario. "Escenarios para la descentralización municipal: el caso de la salud", en Estudios Municipales, No. 20, 1988.
} 
ALINA DEL CARMEN NETTEL BARRERA

La Secretaría de Salud auxiliará, cuando lo soliciten los estados, en las acciones de descentralización a los municipios que aquéllos lleven a cabo.

El marco normativo de desarrollo en los estados juega un papel trascendental en el crecimiento y consolidación de los municipios dentro de un sistema de salud complejo que involucra a todos los niveles de gobierno y, de hecho, diseña la forma de concebir el derecho a la protección de la salud. La Federación, en este sentido, es un pilar de apoyo al desarrollo del sistema, pero deja un margen de acción amplio a los estados para la consolidación del sistema. Un ejemplo de esto es que la Ley Orgánica Municipal del Estado de Querétaro crea las comisiones permanentes de dictamen (cuerpos consultivos y de evaluación de los distintos ramos administrativos), de entre las cuales destaca la de salud pública, que tiene por competencia la higiene y salubridad en el municipio.

En este trabajo se utilizará el marco normativo local del estado de Querétaro como punto de referencia, por ser uno de los primeros estados de la República que se involucró en el proceso de evolución del sector salud en el país. La actual Ley de Salud del Estado de Querétaro, publicada el 30 de enero de 2010, recoge una concepción amplia del derecho a la protección de la salud en relación con las finalidades que la ley reconoce. ${ }^{10}$ Éstas no se reconducen al contenido de los tratados internacionales en su literalidad, pero sí hacen referencia a la calidad de la vida humana, concepto que se puede relacionar estrechamente con la interpretación jurisprudencial del derecho a una vida digna, en los términos de la Corte Interamericana de Derechos Humanos. Aunado a ello, del contenido de la Ley Estatal de Salud (título séptimo) se desprende una concepción global del derecho a la salud, comprendiendo diversos aspectos en su cuidado, como la educación, la nutrición, los efectos del ambiente (dentro del cual cobra importancia la vigilancia de la calidad del agua para uso y consumo humano), la salud ocupacional e incluso la donación de órganos. Sin embargo, llama la atención que para los efectos del derecho a la protección de la salud, según el artículo 30 de la Ley, se consideren aspectos que en su mayoría se reconducen a la prestación de los

\footnotetext{
${ }_{10}$ El artículo 1 de la ley señala como finalidades de este derecho:

"I. El bienestar biopsicosocial de los seres humanos, para contribuir al ejercicio pleno de sus capacidades;

II. Prolongar y mejorar la calidad de la vida humana;

III. Proteger y fortalecer los valores que coadyuven a la creación, conservación y disfrute de condiciones de salud que contribuyan al desarrollo social;

Iv. Promover actitudes solidarias y responsables de la población en la preservación, conservación, mejoramiento y restauración de la salud;

v. El disfrute de servicios de salud y de asistencia social que satisfagan eficaz y oportunamente las necesidades de la población, sin que exista ningún tipo de discriminación;

v. El conocimiento para el adecuado aprovechamiento y utilización de los servicios de salud, y

VII. El desarrollo de la enseñanza y la investigación científica para la salud".
} 
servicios médicos, con las siguientes excepciones: "la educación para la salud, la promoción del saneamiento básico y el mejoramiento de las condiciones sanitarias del medio ambiente"; "la asistencia de grupos vulnerables", y una cláusula residual que recoge cualquier otra disposición legal. En suma, existen ciertos aspectos de la ley estatal que se ajustarían a la construcción de una auténtica cultura del derecho a la salud, o a la protección de la salud de acuerdo con un espíritu garantista; sin embargo, parece mantenerse presente la idea de que la salud esencialmente se relaciona con las formas de atención médica de las enfermedades.

\section{Las competencias otorgadas a los municipios por el artículo 115 de la Constitución mexicana}

El derecho a la salud, como un derecho humano reconocido en diversos instrumentos nacionales e internacionales, ha inspirado el orden jurídico interno de México. Esta realidad no debe verse disociada sino complementaria de otros mandatos constitucionales que abordan la efectividad de este derecho; tal es el caso de las competencias otorgadas por la Constitución a los municipios, ${ }^{11}$ siempre que tengan una relación estrecha con la protección de la salud. Precisamente en este punto radica la doble vertiente de obligaciones para los municipios en materia de salud, pues, por una parte, se trata de abordar la temática desde la responsabilidad de las autoridades administrativas en la promoción, respeto, protección y garantía de los derechos humanos de acuerdo con la exigibilidad de los compromisos adquiridos por México a través de los tratados internacionales. Por otro, se debe reconocer que en materia de salud, las competencias otorgadas expresamente por el artículo 115 de la Constitución se relacionan estrechamente con una concepción amplia del derecho a la salud si se observan como elementos indispensables para el sostenimiento de estándares de una calidad de vida digna y de protección del medio ambiente saludable.

\footnotetext{
"Tras la reforma de 1983 al artículo 115 de la Constitución (publicada en el Diario Oficial de la Federación el 3 de febrero de 1983) los ayuntamientos asumen, de acuerdo con la fracción III, una serie de competencias específicas que apenas han sido modificadas sustancialmente en su contenido; sin embargo, el contexto de su desarrollo competencial si se ha visto modificado por la forma de asumir las competencias. En 1983, la fracción III señalaba que "los municipios, con el concurso de los estados cuando asi fuere necesario y lo determinen las leyes tendrán a su cargo los siguientes servicios públicos". Posteriormente, tras la reforma de 1999 (publicada en el Diario Oficial de la Federación el 23 de diciembre) la fracción III señala que los "municipios tendrán a su cargo las funciones y los servicios públicos siguientes". Este cambio se relaciona con que se reconozca al municipio como "un verdadero orden de gobierno y no como una mera instancia de administración" siempre supeditada a otros niveles de gobierno, especificamente el estatal. Sobre los aspectos positivos y negativos de la reforma de 1999 véase Rendón Huerta Barrera, Teresita. Diagnóstico y diseño de la reglamentación municipal en México, Universidad de Guanajuato, Guanajuato, 2011, p. 26.
} 
La fracción 11 del artículo 115 señala expresamente una serie de funciones y servicios públicos que los municipios deberán asumir. Entre ellos se destacan, por su relación con el derecho a la salud, los relacionados con los incisos:

a) El agua potable, el drenaje, el alcantarillado, y el tratamiento y disposición de las aguas residuales.

b) Limpia, recolección, traslado, tratamiento y disposición final de residuos.

c) Mercados y centrales de abastos.

d) Panteones.

e) Rastro.

f) Calles, parques y jardines, y su equipamiento.

Todas estas encomiendas constitucionales tienen un trasfondo de salud pública y no se trata de una coincidencia, ya que la existencia del municipio, como nivel de gobierno más cercano a la población, ${ }^{12}$ es la sede de satisfacción o decepción de las necesidades de los servicios públicos, relacionados más íntimamente con el desarrollo de las condiciones de vida, de una vida digna.

Específicamente, sobre la relación entre el derecho a la protección de la salud y las competencias municipales constitucionales, se recuerda la naturaleza simbiótica de sus objetivos. De esto encontramos evidencias en diversas normas, en especial todas aquellas que relacionan la salubridad del agua o el medio ambiente con la salud, cualquiera que sea el ámbito competencial en el cual se desarrollen. El artículo 30 de la Ley de Salud de Querétaro es un buen ejemplo de lo anterior, al relacionar el derecho a la protección de la salud con las "condiciones sanitarias del ambiente". Éste puede configurarse como un concepto jurídico indeterminado pero no confuso, pues simplemente abarca todas aquellas situaciones que perjudiquen el ambiente. Pensemos en una deficiente red de drenaje, alcantarillado o disposición de aguas residuales, que puede implicar la contaminación de alimentos, bebidas o la transmisión de enfermedades por contacto; recordemos también que la mala gestión de los residuos, ${ }^{13}$ lentitud, irregularidad o la deficiencia en los medios y formas de recolección se relaciona con la suciedad en las calles, la transmisión de enfermedades y la exposición a peligros como tropiezos o cortaduras; de la gestión de los mercados, centrales

\footnotetext{
12 Este hecho se corrobora desde una perspectiva histórica, pues desde la época colonial los municipios cumplian algunos mandatos en relación con la salud, e incluso la Constitución de Cádiz encomendó la policía de salubridad a los municipios. Véase Ruiz de Chávez, Manuel. "La salud y el...", op. cit., p. 22.

${ }^{13}$ Los casos más dramáticos implican municipios que depositan los residuos al aire libre sin control, "provocando enfermedades y focos de infección donde proliferan plagas nocivas para el ser humano y para la comunidad en su conjunto". Véase Diaz Diaz, Fulgencio. "Residuos sólidos municipales", en Altamirano. Revista del H. Congreso del Estado de Guerrero, año 3, No. 16, 2000, p. 342.
} 
de abasto y rastros depende la salubridad en la comercialización y distribución de alimentos (control de origen, enfermedades, tiempo de exposición, etcétera); incluso la gestión de los panteones tiene implicaciones de salubridad pública, pues la inhumación, exhumación y traslado de restos humanos tiene correspondencia con el control de enfermedades. Por desgracia, los casos aquí señalados son una lamentable realidad de muchos municipios rurales y urbanos a lo largo de la república.

El establecimiento y posterior desarrollo de las competencias municipales constitucionales no ha estado exenta de problemática y un amplio sector de la doctrina ha señalado las deficiencias de las reformas de 1983 y 1999 a la Constitución, así como las tareas pendientes. ${ }^{14}$ Entre otras, el fortalecimiento de un verdadero gobierno municipal y su emancipación financiera, ${ }^{15}$ la necesidad de una ley reglamentaria del artículo 115 constitucional y la reforma administrativa, especialmente en materia de prestación de servicios públicos. ${ }^{16}$

En este último caso, la prestación de servicios públicos, como forma de actividad material de las administraciones públicas, radica en el ejercicio de las competencias constitucionales otorgadas a los municipios y, por supuesto, también aquellas otras competencias que les pudieran haber sido transferidas por parte de las entidades federativas. En esta ocasión el debate no debe centrarse en relación con la forma de asumir la prestación de los servicios públicos, es decir, no debe distraernos la cuestión de si se hace o no de forma directa o indirecta, pues lo que atañe a este trabajo es explicar la importancia de que los municipios asuman la tarea de satisfacer determinadas necesidades ciudadanas en relación con el derecho a la salud. Si esto se lleva a cabo directamente, a través de la gestión privada y las concesiones administrativas, 0 incluso por entes de derecho social, ${ }^{17}$ la cuestión trascendental radica en la decisión de los gobiernos municipales de

\footnotetext{
${ }_{14}$ Sobre la problemática en torno a la distribución de competencias entre la Federación, las entidades federativas y los municipios véase Gámiz Parral, Máximo. "Las relaciones del municipio, los estados y el gobierno federal en México. Un nuevo artículo 115 constitucional", en Valencia, SAlvador (coord.). El municipio en México y en el mundo. Primer Congreso Internacional de Derecho Municipal, unAm, Instituto de Investigaciones Jurídicas, México, 2005, pp. 91 y ss. ${ }^{15} \mathrm{Al}$ respecto se ha señalado que el reconocimiento constitucional del municipio como orden de gobierno (tras la reforma de 1999) no se ha traducido a la realidad, pues "el trato oficial de los asuntos municipales es el mismo, el concepto que del municipio se tiene desde la entidad federativa, y no se diga desde la Federación, no se ha modificado; sigue viéndosele como el más insignificante, como el ente manumitido condenado a la penuria financiera; continúa entrampado entre expedientes, datos, procesos y trámites, para acceder a fondos estatales y federales". Véase Rendón Huerta Barrera, Teresita. "Diagnóstico y diseño de la reglamentación municipal...", op. cit., p. 47.

${ }^{16}$ Las vicisitudes en la prestación de los servicios públicos por parte de los gobiernos municipales han sido abordadas por S. Valencia CARMona en relación con las formas de colaboración entre lo público y lo privado de acuerdo con las tendencias privatizadoras de las últimas décadas. Véase Valencia Carmona, Salvador. "Constitución, municipio y reforma", en Valencia, SAlvador (coord.). El municipio en México..., cit., pp. 91 y ss.

${ }_{17}$ L. J. BéAR Rivera recuerda la posibilidad de que los servicios públicos se presten a través de este tipo de entidades, como sociedades de producción rural, cooperativas, etcétera, que colaboran con el Estado "como prestador de
} 
asumir la responsabilidad de esas necesidades. Uno u otro modelo, antes que temprano, finalmente habrian de exigir resultados materiales sobre las responsabilidades que implican las competencias municipales. Lo anterior se puede sostener si se recuerda la importancia del control en el otorgamiento y desarrollo de las concesiones administrativas para la prestación de los servicios públicos. En efecto, el adecuado control de las concesiones administrativas respecto de la forma y medios de prestación de los servicios públicos por parte de entes privados mantiene un vínculo muy importante $-y$ muchas veces despreciado- entre las administraciones y los servicios. Respecto de su otorgamiento, implican la propia configuración del servicio, el cómo quiere el municipio que se presten los servicios (estándares de calidad, accesibilidad, asequibilidad, etcétera); respecto de su desarrollo, la administración tiene la capacidad de continuar velando por la forma en que se prestan los servicios públicos a través de figuras clave como la sanción, la rescisión o el rescate. ${ }^{18}$

En el mismo sentido, es esencial considerar estrategias alternativas a la rígida distinción tradicional entre servicio público y las exigencias del mercado, pues ambas pueden convivir bajo los postulados de los derechos sociales que tradicionalmente han legitimado la actividad prestacional de las administraciones públicas. Un ejemplo lo encontramos en el concierto como fórmula de articulación entre los sectores público y privado en la regulación de los servicios de interés general no económicos de acuerdo con la configuración de la Unión Europea de los servicios públicos, específicamente aquellos considerados de interés general. Esta fórmula trata de distinguir entre aquellos servicios que tienen un componente económico "tanto en su gestión por la eficiencia, tanto en su conexión con el conjunto de la actividad económica de la que son sectores básicos $\mathrm{y}$ fundamentales", ${ }^{19}$ tales como el transporte, energía, servicios postales, etcétera, y aquellos otros servicios que no tienen un componente económico sino asistencial, "característicos del Estado social”, como la educación o la salud, ámbitos en los que la iniciativa privada se ha mantenido presente de una u otra forma a lo largo de la historia y de las corrientes económicas. Tal como señalé en el párrafo anterior, la clave de esta formulación radica en el reconocimiento de la importancia de los servicios asistenciales y, por tanto, de la responsabilidad del Estado en los objetivos finales de este tipo de servicios, sin perjuicio de la colaboración de sujetos privados bajo una estructura jurídica específica, como es el contrato

servicios hacia sus socios, agremiados o asimilados". Véase BéAR Rivera, José LuIs. Una aproximación a la teoría de los servicios públicos, UBıJus, México, 2012, p. 89.

${ }_{18}$ Véase Martinez Morales, Rafael I. Derecho administrativo. Primer curso, 6a ed., Oxford, México, 2011, pp. 270-272.

19 Véase Esteve PARDo, José. Lecciones de derecho administrativo, Marcial Pons, Madrid, 2011, pp. 432 y sS. 
en el cual se conjugan la rectoría del Estado y la protección de los intereses de los sujetos privados (ya que de ninguna manera se podría permitir que este tipo de figuras impliquen, por su injerencia, la arbitrariedad administrativa).

\section{Los derechos humanos y la actuación de las autoridades municipales en relación con la protección de la salud}

Tal como he tenido oportunidad de señalar, el derecho a la salud, en la concepción amplia del Pacto Internacional de Derechos Económicos, Sociales y Culturales y en la jurisprudencia de la Corte Interamericana de Derechos Humanos, crea un vínculo entre este derecho y la actuación de las administraciones públicas municipales, en ejercicio de las competencias constitucionales que tienen un impacto en la salubridad del medio ambiente. Por otra parte, las reformas de junio de 2011 a diversos artículos de la Constitución para albergar la más amplia protección de los derechos humanos crean condiciones para exigir una actuación administrativa coherente con su respeto, más aún si estos derechos están reconocidos (aunque no con el mismo alcance) en la propia Constitución mexicana como derechos fundamentales..$^{20} \mathrm{Y}$ es que incluso por su misma naturaleza, el derecho a la salud y los servicios públicos municipales son interdependientes y necesitan unos de otros para conseguir sus objetivos. No sólo debemos preguntarnos si las autoridades municipales están conscientes de este marco de actuación, sino también de cómo piensan abordarlo.

Desde un punto de vista tradicionalmente positivista podemos recuperar determinados marcos normativos como la Ley de Salud del Estado de Querétaro, la cual, en el artículo 5, establece que los ayuntamientos son autoridades sanitarias en sus respectivos ámbitos competenciales, lo que proporciona un parámetro de acción y de responsabilidad en materia de salud como órgano de gobierno de los municipios. Además, el Consejo de Salud del Estado de Querétaro se integra, entre otros cargos públicos, por los presidentes de los consejos municipales de salud, de acuerdo con el artículo 9. Esta estructura orgánica de la administración sanitaria juega un papel esencial como punto de partida para la protección del derecho a la salud, siempre que sea efectiva. ${ }^{21}$ Sin menoscabo de esta realidad,

\footnotetext{
20 Véase Carbonell, Miguel. "Los derechos fundamentales en México", 4a ed., Porrúa-unam-CndH, México, 2011.

${ }^{21}$ Ignacio F. Herrerias Cuevas recuerda que la Corte Interamericana de Derechos Humanos, en relación con el caso Radilla Pacheco vs. México, sentencia del 23 de noviembre de 2009, considera que "no sólo la supresión o expedición de las normas de derecho interno garantizan los derechos contenidos en la Convención Americana, de conformidad a la obligación comprendida en el artículo 2 de dicho instrumento. También se requiere el desarrollo de prácticas estatales conducentes a la observancia efectiva de los derechos y libertades consagrados en la misma. En consecuencia,
} 
debemos tener presente el nuevo paradigma sobre el que se fundamenta la concepción de los derechos humanos en México. Sin desconocer el pragmatismo de contar con este tipo de marcos de actuación, lo cierto es que es necesario impulsar una nueva concepción de los municipios y de sus propias responsabilidades, sobre todo teniendo éstas un impacto directo en los derechos fundamentales.

No debemos olvidar que la doctrina más acreditada en materia de derechos fundamentales ha señalado que las facultades $u$ obligaciones de los distintos niveles de gobierno en materia de derechos humanos no interfieren con el sistema de distribución de competencias previsto en el derecho interno. Una autoridad no puede excusarse del cumplimiento de los tratados internacionales basándose en la posible afectación de esferas competenciales. ${ }^{22}$ Por una parte, porque el propio derecho internacional, particularmente la Convención Americana sobre Derechos Humanos en el artículo 28, prevé la adopción de medidas por parte de los Estados (que tienen como forma de Estado la Federación) para evitar este tipo de conflictos. Por otra parte, porque tras la reforma de 2011 y la adopción del párrafo tercero del artículo 1 de la Constitución, todas las autoridades, dentro de sus respectivos ámbitos competenciales, son sujetos de obligaciones en materia de derechos humanos.

\section{Conclusiones}

El esfuerzo por reconocer y concretar el protagonismo del municipio en la vida nacional implica mucho más que reformas constitucionales en el ámbito municipal y demás normas federales y estatales. El objetivo debe centrarse en otorgarle la capacidad de observar el impacto de sus acciones en el proceso de construcción del país, de un país más justo y digno. En este modelo, al que debemos aspirar, los derechos humanos son elementos indispensables. Es por esta razón que se debe reconocer que las áreas estratégicas, como la salud, en el conjunto de la actuación administrativa municipal, implica mucho más que formalismos en la ejecución de las competencias otorgadas por la Constitución o por normas federales o estatales; está íntimamente relacionada con el respeto a los derechos humanos y con la propia construcción de una comunidad saludable.

La relación entre los derechos humanos y el ejercicio de competencias municipales constitucionales no debe quedar reservada a la doctrina o a ámbitos especializados de actuación municipal. Es necesario que se divulgue y que sea

la existencia de una norma no garantiza por sí misma que su aplicación es adecuada". Véase HeRreRias Cuevas, IgNaCio Francisco. Control de convencionalidad y efectos de las sentencias, ubiuss, México, 2012, p. 80.

22 Véase Carbonell, Miguel. "Las obligaciones del Estado en el artículo $1^{\circ}$ de la Constitución...", op. cit., pp. 67 y 68. 
un interés habitual en el quehacer de las administraciones municipales, pues sólo de esta forma se podrá conseguir una concientización de la importancia de la adecuada prestación de servicios públicos que garanticen una vida digna a los ciudadanos. No se puede menospreciar el bagaje de instrumentos jurídicos que proporciona el derecho internacional y que ilustra el cómo deben abordar los municipios las obligaciones de promover, respetar, proteger y garantizar los derechos humanos. Por el contrario, estos instrumentos son fundamentales y deben integrarse a documentos básicos que orientan la actuación de las autoridades administrativas. Finalmente, el nuevo paradigma de los derechos humanos en México debe traducirse en mecanismos útiles que orienten la prestación de los servicios públicos más elementales. 